\title{
A country bug in the city: urban infestation by the Chagas disease vector Triatoma infestans in Arequipa, Peru
}

\author{
Stephen Delgado ${ }^{1,2}$, Kacey C Ernst ${ }^{2}$, María Luz Hancco Pumahuanca ${ }^{3}$, Stephen R Yool ${ }^{1}$, Andrew C Comrie ${ }^{1}$, \\ Charles R Sterling ${ }^{4}$, Robert H Gilman ${ }^{3,5}$, César Náquira ${ }^{3}$, Michael Z Levy ${ }^{6 *}$ and the Chagas Disease Working Group \\ in Arequipa, Peru
}

\begin{abstract}
Background: Interruption of vector-borne transmission of Trypanosoma cruzi remains an unrealized objective in many Latin American countries. The task of vector control is complicated by the emergence of vector insects in urban areas.

Methods: Utilizing data from a large-scale vector control program in Arequipa, Peru, we explored the spatial patterns of infestation by Triatoma infestans in an urban and peri-urban landscape. Multilevel logistic regression was utilized to assess the associations between household infestation and household- and locality-level socioenvironmental measures.
\end{abstract}

Results: Of 37,229 households inspected for infestation, 6,982 (18.8\%; 95\% Cl: $18.4-19.2 \%)$ were infested by T. infestans. Eighty clusters of infestation were identified, ranging in area from 0.1 to 68.7 hectares and containing as few as one and as many as 1,139 infested households. Spatial dependence between infested households was significant at distances up to 2,000 meters. Household T. infestans infestation was associated with household-and locality-level factors, including housing density, elevation, land surface temperature, and locality type.

Conclusions: High levels of $T$. infestans infestation, characterized by spatial heterogeneity, were found across extensive urban and peri-urban areas prior to vector control. Several environmental and social factors, which may directly or indirectly influence the biology and behavior of T. infestans, were associated with infestation. Spatial clustering of infestation in the urban context may both challenge and inform surveillance and control of vector reemergence after insecticide intervention.

Keywords: Triatoma infestans, Chagas disease, Urban infestation, Vector control, Spatial analysis, Multilevel logistic regression

\section{Background}

Chagas disease, also known as American trypanosomiasis, is caused by the protozoan parasite Trypanosoma cruzi and is endemic in Latin America. Typically, T. cruzi is transmitted to humans via the infected excretions of various bloodfeeding triatomine insect species, including Triatoma infestans. Less commonly, infection may result from congenital transmission, blood transfusion, organ transplantation, and

\footnotetext{
* Correspondence: mzlevy@mail.med.upenn.edu

${ }^{6}$ Department of Biostatistics and Epidemiology, University of Pennsylvania, 714 Blockley Hall, 423 Guardian Drive, Philadelphia, Pennsylvania 19104, USA Full list of author information is available at the end of the article
}

incidental ingestion of parasite-contaminated food or drink [1]. Chagas disease is characterized by an acute phase, which lasts $6-8$ weeks, and a chronic phase, which persists for life. In most cases, both the acute and chronic phases of infection are asymptomatic. However, $10-40 \%$ of cases, depending on the geographic region, progress over a period of years to chronic disease, including potentially fatal cardiac and gastrointestinal disorders [2]. Globally, eight million persons are infected with $T$. cruzi, resulting in 11,000 deaths and the loss of 430,000 disability-adjusted life years (DALYs) annually $[3,4]$.

\section{Biomed Central}


Prevention and control of Chagas disease are achieved primarily via large-scale insecticide application initiatives [5], and T. infestans, which lives predominantly in and around human households, is a principal target for vector control [2]. While the Southern Cone Initiative has succeeded in interrupting T. cruzi transmission by $T$. infestans in Brazil, Chile, and Uruguay [6,7], T. infestans-mediated T. cruzi transmission persists in parts of Argentina, Bolivia, Paraguay, and Peru [8,9]. Moreover, efforts to eliminate $T$. infestans have been complicated by the expansion of this species from sparsely populated rural regions into densely populated urban areas $[10,11]$.

While the ecology of $T$. infestans infestation in rural environments has been studied extensively, urban infestation by this insect has been investigated only preliminarily. To advance understanding of vector infestation in the urban context, this study examines infestation by $T$. infestans across an urban and peri-urban landscape prior to implementation of vector control. Our study focuses on Arequipa, Peru, which lies in an area with extensive $T$. infestans infestation and epidemic T. cruzi transmission $[8,12]$. Utilizing data collected from multiple sources at multiple spatial scales, we employ spatial point pattern analysis and multilevel logistic regression to elucidate spatial patterns in infestation by $T$. infestans and to assess associations between several environmental and social factors and $T$. infestans infestation in an urban landscape. In particular, the effects of housing density, land surface temperature, and elevation were evaluated at the household level, while the effects of urban shantytowns, which have been identified as areas at higher risk for infestation by Chagas diesease vectors and vector-borne transmission of T. cruzi, were evaluated at the locality level [11,13-15].

\section{Results}

Triatoma infestans were found in 6,982 (18.8\%; 95\% CI: $18.4-19.2 \%$ ) of the 37,229 study households. Prevalence of household infestation varied widely across the study area, with spatially smoothed estimates ranging from 0.0 to $77.9 \%$ (Figure 1). Eighty areas were identified that exceeded the upper limit of a 999-iteration random labeling simulation of the kernel density estimate ratio of infested households versus all study households. These clusters of infestation, which ranged in area from 0.1 to 68.7 hectares, contained as few as 1 and as many as 1,139 infested households. In total, the clusters encompassed 3,278 (46.9\%) of the 6,982 infested households. The K-function difference for infested versus non-infested households exceeded the upper limit of a 999-iteration random labeling simulation at all 100-meter increments up to 2000 meters.

Univariate logistic regression showed statistically significant relationships between household infestation and housing density, elevation, and land surface temperature. No significant correlation was found between housing density and elevation $(r=0.13)$, between housing density and land surface temperature $(r=0.02)$, or between elevation and land surface temperature $(r=0.02)$. For housing density, odds of infestation were approximately two times higher in the highest versus the lowest quintile. For elevation, odds of infestation were higher only in the third and fourth quintiles. Odds of infestation increased $8 \%$ with each $1^{\circ} \mathrm{C}$ increase in land surface temperature. Covariates remained statistically significant in the multivariate model, with a modest increase in the odds of infestation associated with land surface temperature, and moderate decreases in the odds of infestation associated with housing density and elevation (Table 1).

Multilevel logistic regression represented an improvement over ordinary logistic regression, and the data were best fit by a model including household-level covariates, a locality-level covariate, and locality-level random effects (Table 2).

Spatial autocorrelation in deviance residuals was distinctly decreased in the best-fit multilevel model versus the ordinary multivariate model (Figure 2).

Locality-level random effects were substantial. The median odds ratio (MOR), which is the median value of the odds ratio when comparing a higher to a lower risk locality, indicated that the median odds of infestation were two and one-half times greater in higher versus lower risk localities (Table 2).

The effect of the locality-level covariate, locality type, was also significant. Households located in shantytowns had $75 \%$ higher odds of infestation than households situated in other locality types. However, the interval odds ratio (IOR), which is the interval between the 10th and 80th percentile centered on the median value of the distribution of odds ratios for locality type, included the value one. This indicates that the effect of locality type is not as strong as the locality-level random effect (Table 2).

Household-level effects all remained statistically significant. Odds of infestation increased 10\% with each $1{ }^{\circ} \mathrm{C}$ increase in land surface temperature, which was similar to the estimate from ordinary multivariate logistic regression. The highest housing density quintile had $75 \%$ higher odds of infestation relative to the lowest quintile, which is slightly diminished compared to results from the ordinary multivariate model. The fourth elevation quintile had greater than twice the odds of infestation relative to the lowest quintile, but the highest quintile showed only 50\% higher odds of infestation relative to the lowest quintile. The effect of elevation was substantially increased in the multilevel versus the ordinary multivariate logistic regression model (Table 2). 


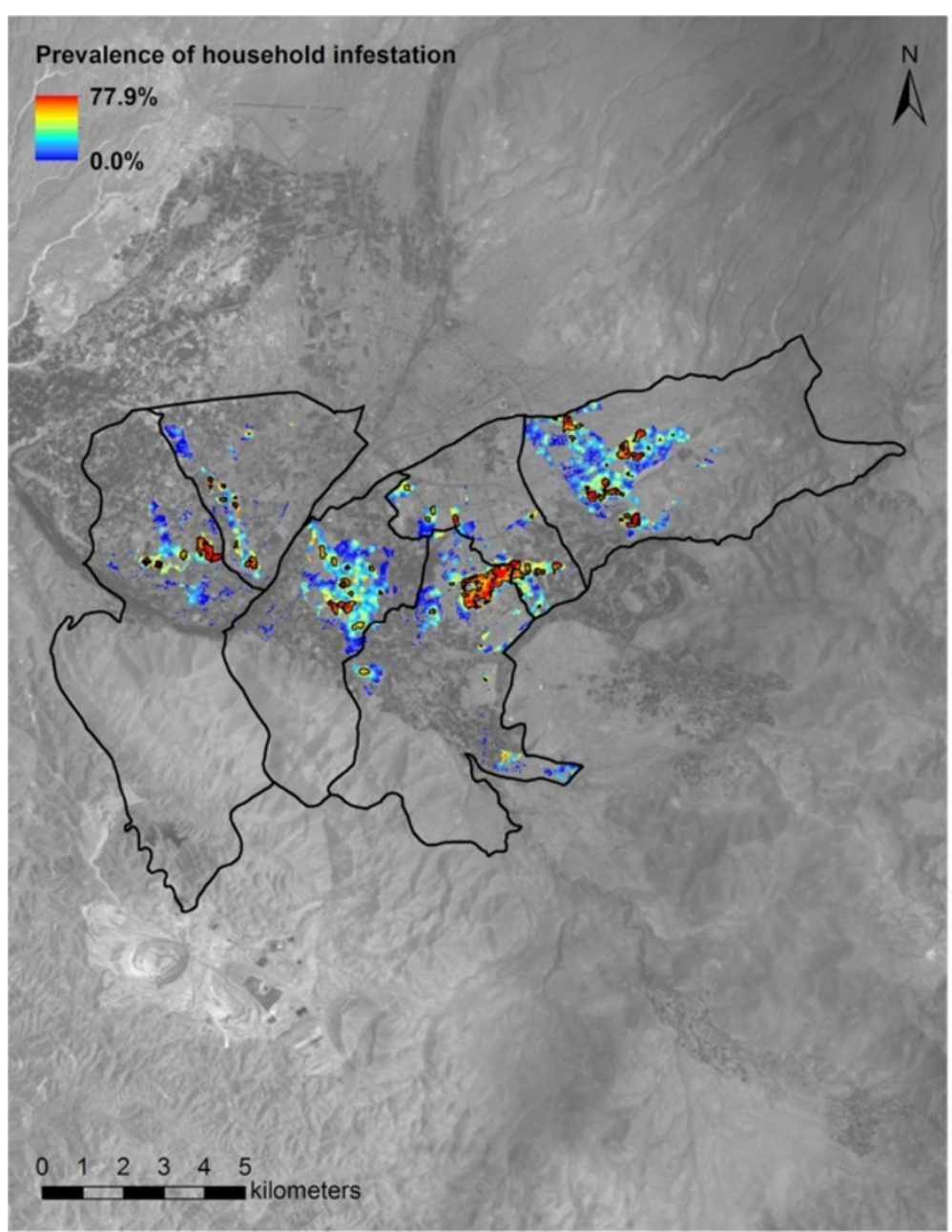

Figure 1 Kernel-smoothed prevalence of household Triatoma infestans infestation. Spatially smoothed prevalence of household infestation varied from $0.0-77.9 \%$ across the study area. Colored pixels outlined in black represent statistically significant clusters of infestation. A grayscale Landsat 5 Thematic Mapper (TM) band 3 image (15 December 2008, WGS 84 UTM 19S) shows landscapes encompassed by the six study area districts and surrounding areas.

\section{Discussion}

Infestation by T. infestans has been found in many urban areas in Latin America, including Santiago, Chile [13]; Cochabamba and Sucre, Bolivia [14]; and Arequipa, Peru [11]. In affected areas-urban as well as rural-prevention and control of Chagas disease relies on vector control [5]. While infestation by and control of T. infestans has been extensively examined in the rural context, infestation in the urban milieu is less well understood. Utilizing spatial and multilevel logistic regression analysis of data collected from multiple sources at multiple spatial scales, we offer insights into the dynamics of T. infestans infestation in an urban landscape.

Prior to implementation of vector control, urban and peri-urban households in Arequipa were extensively infested by $T$. infestans. The intensity of infestation was spatially heterogeneous, with areas of very low and very high prevalence of infestation. Numerous clusters of infestation, small and large, were found across the six study districts, indicating that urban and peri-urban areas are conducive to the proliferation and dispersion of $T$. infestans. In rural landscapes, $T$. infestans have been shown to actively disperse by walking or flying at distances up to approximately 100 or 2,000 meters, respectively [16,17]. In a separate study in urban Arrequipa, streets were shown to be significant barriers to the dispersion of T. infestans, and to strongly influence the spatial distribution of infestation [18]. In contrast, flight has been observed as a main mechanism of infestation in urban San Juan, Argentina [19]. In the present study, spatial dependence between infested households was observed at distances from 0 to 2,000 meters, suggesting that urban $T$. infestans may disperse by walking at shorter spans that do not cross city streets, as well as by flying at longer distances across urban blocks. 
Table 1 Results of univariate and multivariate logistic regression

\begin{tabular}{|c|c|c|c|c|c|c|}
\hline \multirow[b]{2}{*}{ Range } & \multirow[b]{2}{*}{ Inspected } & \multirow[b]{2}{*}{ Infested } & \multicolumn{2}{|c|}{ Univariate logistic regression } & \multicolumn{2}{|c|}{ Multivariate logistic regression } \\
\hline & & & Odds ratio & $95 \% \mathrm{Cl}$ & Odds ratio & $95 \% \mathrm{Cl}$ \\
\hline \multicolumn{3}{|c|}{ Housing density (households/hectare) } & & $\mathrm{AlC}=32,993$ & & \\
\hline $2-24^{*}$ & 6,866 & 831 & 1.00 & & 1.00 & \\
\hline $24-30$ & 6,855 & 1,148 & 1.46 & $1.33-1.61$ & 1.38 & $1.26-1.53$ \\
\hline $30-34$ & 6,848 & 1,434 & 1.92 & $1.75-2.11$ & 1.79 & $1.63-1.97$ \\
\hline $34-39$ & 6,861 & 1,582 & 2.18 & $1.99-2.39$ & 2.02 & $1.84-2.22$ \\
\hline $39-77$ & 6,845 & 1,534 & 2.10 & $1.91-2.30$ & 1.90 & $1.73-2.09$ \\
\hline \multicolumn{3}{|c|}{ Land surface temperature $\left({ }^{\circ} \mathrm{C}\right)$} & & $\mathrm{AIC}=33,300$ & & \\
\hline $26-40$ & 34,275 & 6,529 & 1.08 & $1.06-1.10$ & 1.10 & $1.08-1.12$ \\
\hline \multicolumn{3}{|c|}{ Elevation (meters above sea level) } & & $\mathrm{AIC}=33,134$ & & \\
\hline $2,120-2,260^{*}$ & 6,866 & 1,085 & 1.00 & & 1.00 & \\
\hline $2,260-2,300$ & 6,996 & 1,089 & 0.98 & $0.90-1.08$ & 0.82 & $0.74-0.90$ \\
\hline $2,300-2,350$ & 6,716 & 1,526 & 1.57 & $1.44-1.71$ & 1.31 & $1.20-1.44$ \\
\hline $2,350-2,450$ & 6,852 & 1,612 & 1.64 & $1.50-1.79$ & 1.45 & $1.33-1.59$ \\
\hline \multirow[t]{2}{*}{$2,450-2,670$} & 6,845 & 1,217 & 1.15 & $1.05-1.26$ & 1.06 & $0.96-1.16$ \\
\hline & & & & & & $\mathrm{AIC}=32,724$ \\
\hline
\end{tabular}

${ }^{*}$ Referent category.

95\% Cl: 95\% confidence interval.

AIC: Akaike information criteria.

Identifying extant clusters of infestation prior to vector control may have critical consequences for implementing effective surveillance of vector reemergence subsequent to vector control. In an extensive but sparsely populated rural area in the Gran Chaco of Argentina, reinfestation by $T$. infestans tended to cluster in areas where infestation was aggregated prior to vector control [20]. Infestation clusters in an extensively and densely populated urban area may be similarly problematic. The existence of numerous infestation clusters in Arequipa, many encompassing large areas and many households, should be priority areas for surveillance and control by the GRSA. Where feasible, utilization of a geographic information system to monitor $T$. infestans reemergenceas well as other health risks and outcomes-might be a cost effective investment for resource-constrained public health institutions in Arequipa, and elsewhere in the developing world $[21,22]$.

Spatial heterogeneity in urban infestation by $T$. infestans is likely influenced by myriad factors operating at multiple spatial scales. We evaluated only a few features, which were chosen based on ecological plausibility and data availability. In ordinary univariate and multivariate logistic regression, housing density, elevation, and land surface temperature were all positively, if not always linearly, associated with household infestation. Housing density may mediate vector dispersal. In higher density urban areas, new habitats and blood sources found in nearby houses are located at short distances from one another, thereby facilitating dispersal of refuge- or blood-seeking vectors. Also, attraction to light influences the dissemination of $T$. infestans, and the plentiful light sources in higher density urban areas may promote insect dispersal [23]. Land surface temperature may affect vector biology and behavior. Both laboratory and field experiments demonstrate that $T$. infestans flight initiation increases at higher temperatures $[17,24]$, thereby promoting vector dispersal in warmer urban areas. Laboratory studies also indicate that higher temperatures increase $T$. infestans feeding and development rates $[25,26]$, and blood meal seeking is reportedly the principal cause for dispersion of triatomines [23]. In warmer urban areas, increased feeding and development may result in increased vector dispersal. Elevation may act indirectly through socioeconomic circumstances, rather than directly through biophysical constraints. In Arequipa, lower socioeconomic status populations, often rural-to-urban migrants, typically inhabit the higher elevation hillsides, while higher socioeconomic status populations usually reside in lower elevation valleys [27]. As such, higher infestation at higher elevation in Arequipa may be attributable to two factors: passive introduction of insects resulting from seasonal migration to and from nearby rural areas where $T$. infestans are prevalent, and substandard living conditions that provide habitats suitable for T. infestans infestation [27]. The slight decrease in infestation at the highest elevations may result from the relatively recent inhabitation of these areas, leaving little time for infestation to have occurred. Elevation is unlikely to be a biophysical constraint for infestation in 
Table 2 Results of multilevel logistic regression

\begin{tabular}{|c|c|c|c|}
\hline & Model 0 & Model 1 & Model 2 \\
\hline \multicolumn{4}{|c|}{ Household-level fixed effects: odds ratio $(95 \% \mathrm{Cl})$} \\
\hline \multicolumn{4}{|c|}{ Housing density (households/hectare) } \\
\hline $2-24^{*}$ & & 1.00 & 1.00 \\
\hline $24-30$ & & $1.23(1.10-1.37)$ & $1.22(1.10-1.37)$ \\
\hline $30-34$ & & $1.44(1.29-1.61)$ & $1.44(1.29-1.61)$ \\
\hline $34-39$ & & $1.57(1.39-1.76)$ & $1.56(1.39-1.75)$ \\
\hline $39-77$ & & $1.74(1.54-1.97)$ & $1.73(1.53-1.96)$ \\
\hline \multicolumn{4}{|c|}{ Land surface temperature $\left({ }^{\circ} \mathrm{C}\right)$} \\
\hline $26-40$ & & $1.10(1.08-1.13)$ & $1.10(1.08-1.13)$ \\
\hline \multicolumn{4}{|c|}{ Elevation (meters above sea level) } \\
\hline $2120-2260^{*}$ & & 1.00 & 1.00 \\
\hline $2260-2300$ & & $1.44(1.18-1.76)$ & $1.48(1.21-1.82)$ \\
\hline $2300-2350$ & & $1.89(1.49-2.41)$ & $1.99(1.57-2.53)$ \\
\hline $2350-2450$ & & $2.12(1.63-2.76)$ & $2.28(1.75-2.98)$ \\
\hline $2450-2670$ & & $1.39(1.07-1.82)$ & $1.49(1.14-1.94)$ \\
\hline \multicolumn{4}{|c|}{ Locality-level fixed effects: odds ratio $(95 \% \mathrm{Cl})$} \\
\hline \multirow[t]{2}{*}{ Shantytown } & & & $1.75(1.24-2.47)$ \\
\hline & & & IOR: $(0.30-10.26)$ \\
\hline \multicolumn{4}{|c|}{ Locality-level random effects } \\
\hline Variance $(95 \% \mathrm{Cl})$ & $1.12(0.84-1.49)$ & $1.03(0.77-1.37)$ & $0.95(0.71-1.27)$ \\
\hline Change in variance & & $-8.1 \%$ & $-7.4 \%$ \\
\hline Median odds ratio & 2.74 & 2.63 & 2.54 \\
\hline \multicolumn{4}{|c|}{ Likelihood ratio test ( $p$-value) } \\
\hline v. logistic model ${ }^{\dagger}$ & $<0.0001$ & $<0.0001$ & $<0.0001$ \\
\hline v. multilevel model ${ }^{\ddagger}$ & & $<0.0001$ & 0.0015 \\
\hline AIC & 30,467 & 30,269 & 30,261 \\
\hline
\end{tabular}

*Referent category.

${ }^{+}$Multilevel versus ordinary logistic regression.

${ }^{\ddagger}$ Multilevel model $n+1$ versus model $n$.

95\% Cl: $95 \%$ confidence interval.

IOR: interval odds ratio.

AIC: Akaike information criteria.

the currently populated areas of Arequipa, since T. infestans have been found as high as 3,682 meters above sea level in Argentina [23], well above the elevation of the study area.

Multilevel logistic regression revealed the importance of locality-level contextual effects and substantially diminished spatial autocorrelation present in ordinary logistic regression. The locality-level random effect, which estimates the influence of unobserved contextual effects within each locality, indicates that these unmeasured factors are associated, in median, with substantially higher risk of household infestation. In Arequipa, and elsewhere, urban shantytowns have been identified as areas with higher risk for infestation by Chagas disease vectors, and vector-borne transmission of $T$. cruzi [11,13-15]. We offer further evidence that shantytowns are at higher risk for infestation by $T$. infestans. Controlling for locality-level effects, household-level effects for housing density, elevation, and land surface temperature all remained statistically significant and substantial.

We recognize that our study is limited in many respects. First, while we believe that household location and infestation status data are both precise and accurate, more detailed data regarding the number, life stage, and T. cruzi infection status of insects encountered during the vector control campaign were unavailable. Nor did we have in-depth data regarding households (e.g., construction materials, domestic animals) or their occupants. More detailed data would have likely improved the insights provided by our analyses. Second, we recognize that point-level household covariates are extracted from remote sensing data collected at a 30-meter 

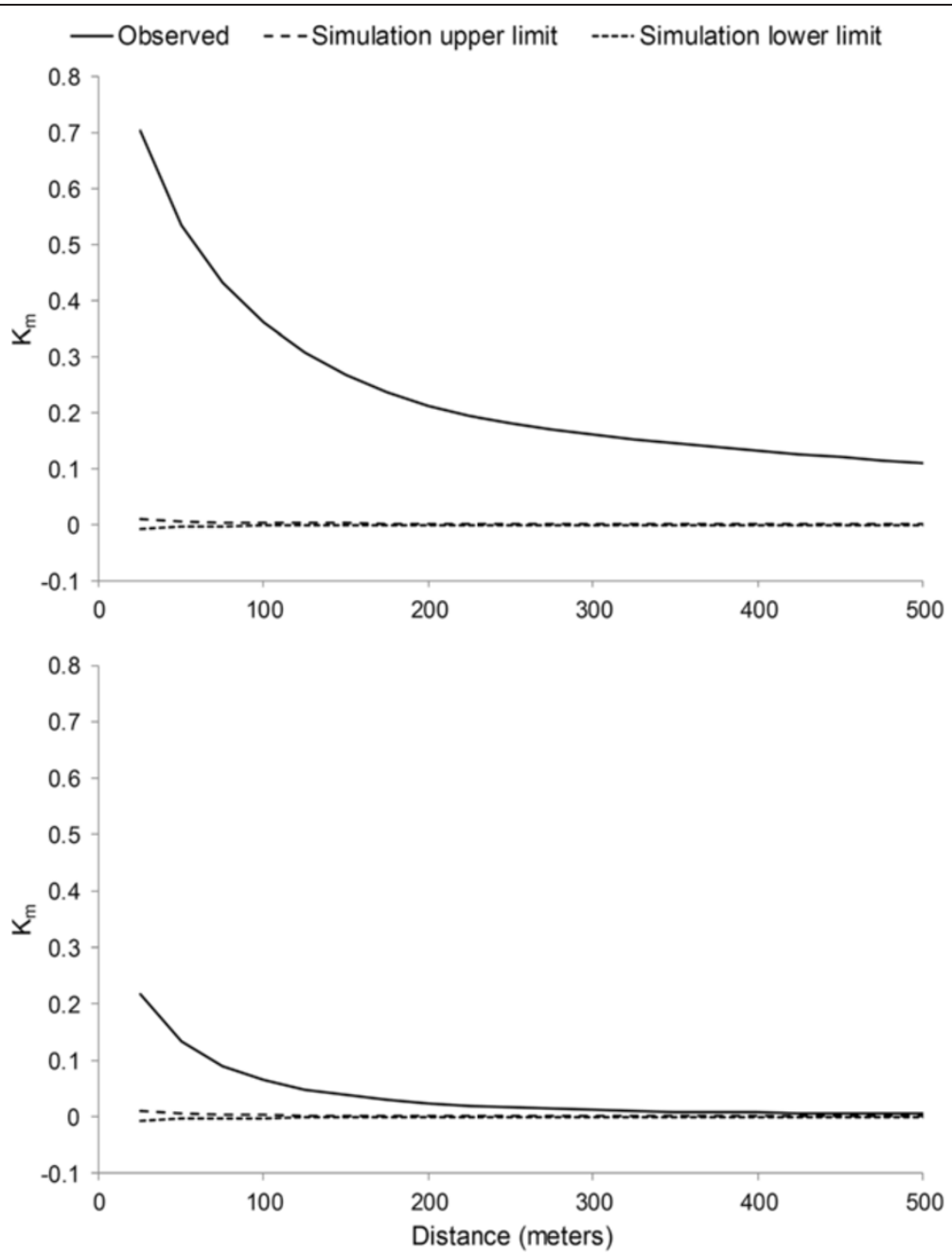

Figure 2 Spatial autocorrelation in deviance residuals for least- and best-fit regression models. Comparison of spatial autocorrelation in the deviance residuals from the ordinary multivariate logistic regression model (upper panel) versus the best-fit multilevel logistic regression model (lower panel). The mark correlation function $\left(\mathrm{K}_{\mathrm{m}}\right)$ may vary between -1 (negative spatial autocorrelation) and +1 (positive spatial autocorrelation), with an expected value of 0 for no spatial autocorrelation. Spatial autocorrelation was substantially reduced, albeit not eliminated, in the best- versus least-fit multivariate logistic regression model.

scale (elevation, land surface temperature) or are spatially smoothed estimates (housing density). We also understand that land surface temperature data do not capture fine-scale temporal variability that occurs across and within days of the year, nor do they describe finescale spatial variation in ambient micro-climatic conditions. These issues of scale could conceivably bias the relative magnitude of observed effects. Third, at the time of data collection, portions of the six study districts were still undergoing vector control. Future analyses of areas recently reached by the vector control campaign, including districts beyond the current study area, may provide deeper and broader insights into urban and peri-urban T. infestans infestation.

The geography and ecology of $T$. infestans-as well as vector species for many other infectious diseases-are changing. Decreasing funding and political will and increasing insecticide resistance are endangering gains made towards interruption of vector-borne transmission of T. cruzi [9]. For many vector-borne diseases in many parts of the world, these are not only public health concerns but also social justice issues, as economically and politically marginalized populations may suffer disproportionately. Many potentially powerful tools (e.g., Google Earth, The R Project for Statistical Computing), data sources (e.g., NASA, NOAA), and spatial and statistical methods are now freely available. Finding novel uses for these resources in conjunction with local knowledge and information-as well as increasing capacity to do socould inspire new perspectives on and solutions to existing and emerging public health problems and their social and environmental causes and consequences. 


\section{Methods}

\section{Study area}

Arequipa (population 864,250) is situated in southwestern Peru and is the country's third most populous province. This study focuses on six of the province's twentynine districts: Jacobo Hunter, Jose Luis Bustamante y Rivero, Paucarpata, Sachaca, Socabaya, and Tiabaya. The districts encompass a geographically contiguous area of 139 square kilometers adjacent to the capital city of Arequipa, and include nearly forty percent of the province's population [28] (Figure 3).

In 2003, the Gerencia Regional de Salud de Arequipa (GRSA) initiated a vector control program to eliminate household infestation by $T$. infestans. The program is ongoing, is implemented on a district-by-district basis, and consists of a simple stepwise process. First, each household is assigned a unique alphanumeric code, and household codes and locations are catalogued on handdrawn maps. Second, trained GRSA personnel go door- to-door, spray all domestic areas and peri-domestic animal enclosures in each household, and inspect for the presence of triatomines, taking advantage of the flushing effect of the insecticide. The presence or absence of $T$. infestans is recorded. Finally, the inspection and insecticide application process is repeated approximately six months later.

\section{Data collection \\ Household data}

Maps of household locations, household unique identifier codes, and dates and results of household $T$. infestans inspections were provided by the GRSA. Within the study area 37,229 households had been inspected for infestation by $T$. infestans and sprayed with insecticide during the period from September 2003 through December 2008. Using GRSA maps and Google Earth imagery, we assigned geographic coordinates to these households, as well as to households within the six study districts

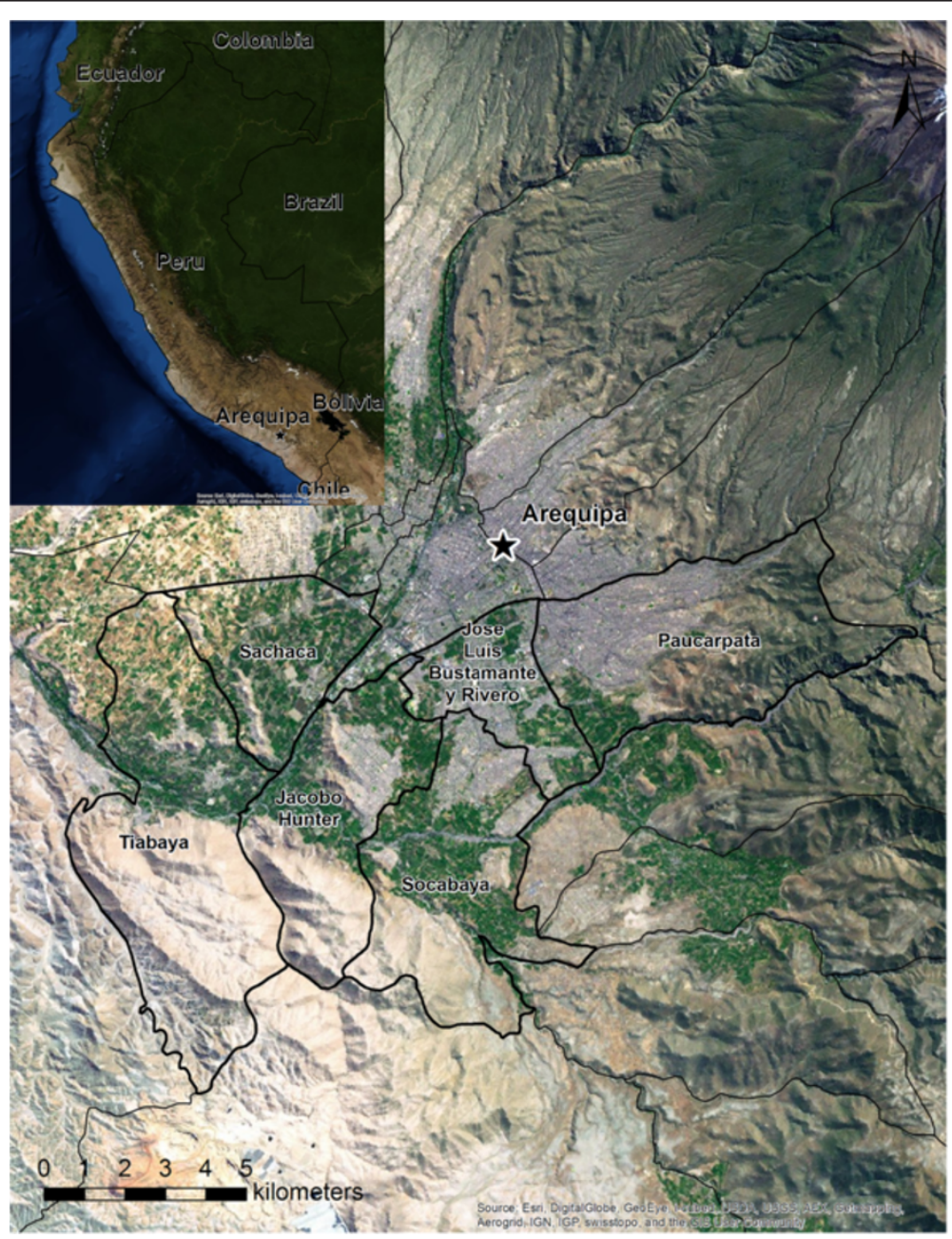

Figure 3 The Arequipa, Peru, study area. Satellite imagery of the six study area districts, the city of Arequipa, and the surrounding area. The inset map shows the locations of Arequipa, Peru, and bordering areas. The study area encompasses a mosaic of urban and peri-urban landscapes. 
that had not as yet been reached by the vector control campaign as of December 2008. Household geographic coordinates, household $T$. infestans infestation status $(0 / 1)$, and household unique identifier codes were stored in a relational database management system for subsequent analysis.

\section{Remote sensing data}

Advanced Spaceborne Thermal Admission and Reflection Radiometer (ASTER) Global Digital Elevation Model Version 2 (GDEM V2) 30-meter-resolution imagery of the study area (ASTGTM2_S17W072) was acquired from the National Aeronautics and Space Administration (NASA) Earth Observing System Data and Information System (EOSDIS) [29]. Landsat 5 Thematic Mapper (TM) 120-meter resolution thermal imagery (band 6: $10.40-12.50 \mu \mathrm{m}$ ) and 30-meter resolution visible (band 3: $0.63-0.69 \mu \mathrm{m}$ ) and nearinfrared (band 4: $0.76-0.90 \mu \mathrm{m}$ ) imagery of the study area (WRS path 3 row 71) were obtained from the United States Geological Survey (USGS) EarthExplorer [30]. Cloud-free images were attained for nine dates in 2008: 18 March, 19 April, 21 May, 24 July, 25 August, 26 September, 12 October, 13 November, and 15 December. A Landsat 5 TM band 3 image acquired on 25 July 1987 was obtained from NASA's Global Orthorectifed Landsat Data Set as reference for geometric correction of 2008 images [31,32].

\section{Census data}

In Peru, census areas are subdivided into departments, provinces, districts, and localities. A database of the locality in which each study household was located was provided by the GRSA, and a census classification of locality types was obtained from the Peru National Institute of Statistics and Informatics (INEI). Locality type categories included city (ciudad), housing development (urbanización), town (pueblo), shantytown (pueblo joven), housing association (asociación de viviendas), housing cooperative (cooperativa de viviendas), annex (anexo), hamlet (caserio), and rural community (comunidad campesina) [33]. The GRSA and INEI databases were joined and each household was assigned a categorical variable specifying locality type for 34,275 of the 37,229 (92.1\%) households with documented T. infestans inspection data.

\section{Data analysis}

\section{Spatial point pattern analysis}

Spatial variation in household infestation by $T$. infestans was evaluated by dividing the kernel-smoothed density of infested households by the kernel-smoothed density of all study households. An isotropic Gaussian smoothing kernel with a standard deviation $(\sigma)$ of 45.7 meters was utilized for this analysis, where $\sigma$ was selected using a likelihood cross-validation method. A 999-iteration random labeling simulation was performed to identify areas where infestation by $T$. infestans was significantly elevated $[34,35]$. The kernel-smoothed density of all georeferenced households $(\mathrm{n}=68,849)$, with $\sigma=27.8$ meters, was estimated for evaluation as a covariate in logistic regression $[35,36]$.

Spatial dependence between households infested by $T$. infestans was assessed by computing the difference in the K-function for infested households and non-infested households at 100-meter increments from 0 to 2000 meters. A 999-iteration random labeling simulation was executed to identify distances at which spatial dependence of infested households was statistically significant [37].

Spatial statistical analyses were conducted using $\mathrm{R}$ (The R Project for Statistical Computing) [38]. Maps of spatial variation in household infestation and household density were constructed using ArcGIS version 10 (ESRI) [39].

\section{Remote sensing image analysis}

Remote sensing data were utilized to derive and extract household point-level estimates of elevation and land surface temperature for evaluation as covariates in logistic regression.

The ASTER GDEM V2 image was projected to the WGS 84 UTM 19S coordinate system and resampled to a 30-meter pixel size to match the projection and spatial resolution of Landsat $5 \mathrm{TM}$ imagery, and elevation data were extracted to household point locations.

Landsat 5 TM and ASTER GDEM V2 images were cropped to a 701-column by 474-row area corresponding to the rectangle bounding the six study area districts. Landsat 5 TM band 3, 4, and 6 images from 2008 were geometrically corrected utilizing a simple root mean square error minimization routine and the Landsat 5 TM band 3 image from 1985 as reference [40]. Atmospheric correction of Landsat 5 TM band 3 and 4 images was performed using a modified dark object subtraction method [41], followed by topographic correction utilizing a Minnaert method [42]. The normalized difference vegetation index (NDVI) was calculated from Landsat 5 TM band 3 and 4 images [43], and land surface emissivity was estimated from NDVI for each date in 2008 [44]. Land surface temperature was derived using Landsat 5 TM band 6 thermal infrared images; land surface emissivity images; and coefficients for atmospheric transmissivity, upwelling atmospheric radiance, and downwelling atmospheric radiance $[45,46]$. Land surface temperature images were overlaid, median land surface temperature was calculated for each raster pixel, and these data were extracted to household point locations. 
Processing of ASTER GDEM V2 and Landsat 5 TM images was conducted using the landsat package version 1.0.8 in $\mathrm{R}$ version 2.15.2 [40]. Atmospheric coefficients were obtained from the Atmospheric Correction Parameter Calculator [47]. ArcGIS version 10 was utilized to create maps of elevation and land surface temperature, and to extract values for these variables to household point locations.

\section{Statistical analysis}

Prevalence of infestation was calculated for the 37,229 households inspected and sprayed for T. infestans. Pearson's correlation coefficient was utilized to assess correlation among candidate continuous covariates for logistic regression modeling. Univariate and multivariate logistic regression were used to evaluate the associations between household infestation and household-level variables, including housing density, elevation, and median land surface temperature (Figure 4). To account for non-linearity in logistic regression, housing density and elevation were converted from continuous to categorical variables based on their respective quintiles. Median land surface temperature was maintained as a continuous variable.

To address spatial dependence among observations and to assess locality-level effects, three multilevel logistic regression models were evaluated: a model including only locality-level random effects (Model 0); a model including household-level covariates and locality-level random effects (Model 1); and a model including household-level covariates, a locality-level covariate, and locality-level random effects (Model 2).

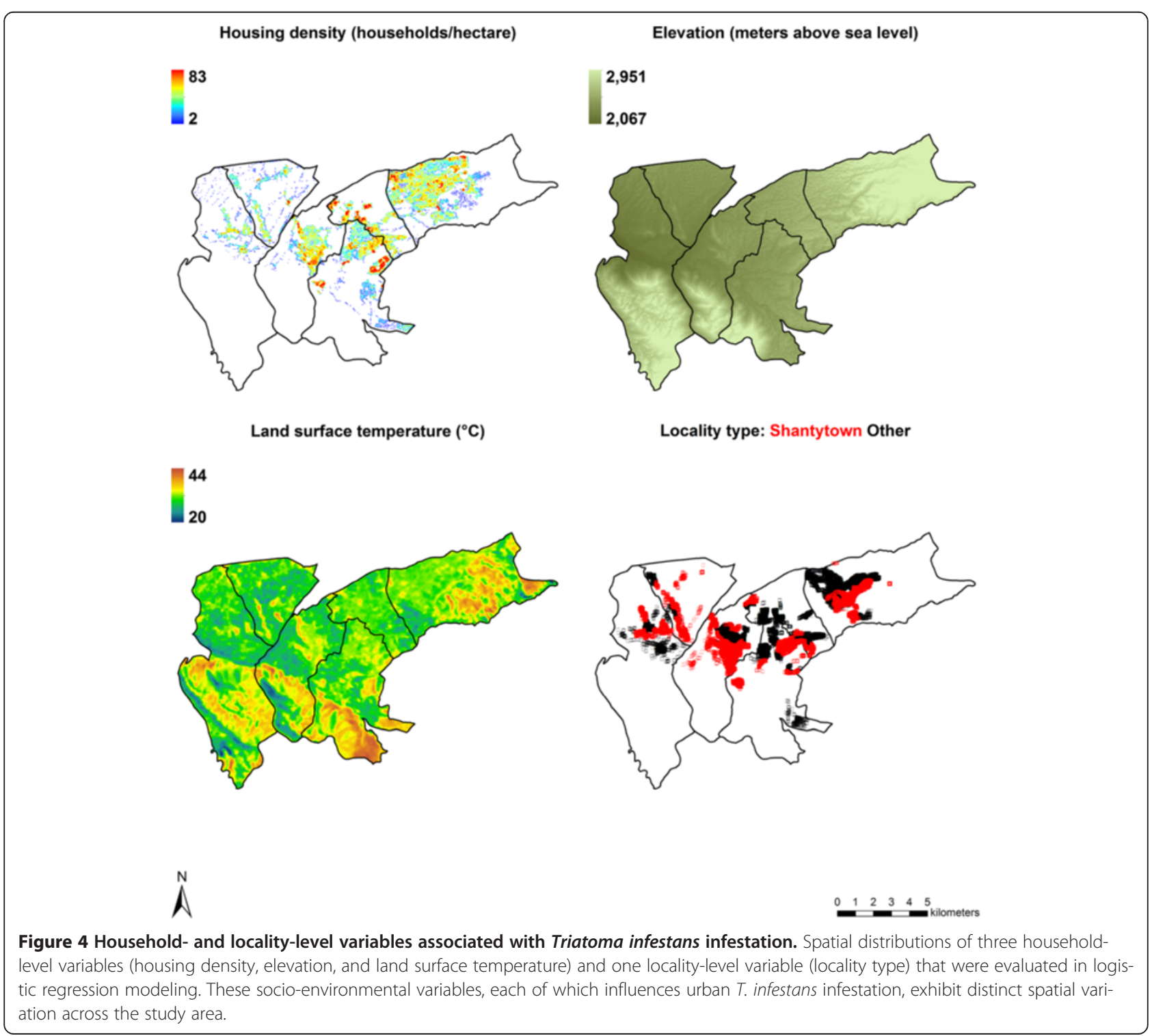


In addition to standard odds ratios, median odds ratios (MOR) were calculated for locality-level random effects, and the interval odds ratio (IOR) were calculated for the locality-level covariate $[48,49]$.

The locality-level covariate is a dichotomous categorization of locality type into shantytown and other. Shantytowns are informal urban population centers composed of blocks or collection of substandard housing, often without urban infrastructure or basic services [33]. In contrast, the category other consists primarily of formal urban population centers, including cities, housing developments, housing associations, and housing cooperatives; and secondarily of formal rural population centers, including towns, hamlets, rural communities, and annexes [33]. In Peru, urban areas are defined as built areas of at least 100 households that are continuously occupied, whereas rural areas are simply defined as built areas outside of urban areas [33]. Among urban locality types, cities correspond to common conceptions of cities, housing developments resemble suburbs, housing associations are residential housing developments with shared living spaces, and housing cooperatives are residential housing developments with shared living spaces. Among rural locality types, towns correspond to common conceptions of rural towns, hamlets are smaller versions of towns, rural communities are communal farming areas, and annexes correspond to unincorporated areas. Locality type information was unavailable for 2,954 (7.9\%) of mapped households. These were omitted from logistic regression modeling, leaving 34,725 households located in 160 localities for regression analyses (Table 3).
Model 0 Locality-level random effects only:

$$
\operatorname{logit}\left[\operatorname{Pr}\left(y_{i j}=1\right)\right]=\beta_{0}+u_{j}
$$

Model 1 Household-level effects and locality-level random effects:

$$
\begin{aligned}
\operatorname{logit}\left[\operatorname{Pr}\left(y_{i j}=1\right)\right]= & \beta_{0}+\beta_{1} \text { density }_{i j}+\beta_{2} \text { elevation }_{i j} \\
& +\beta_{3} \text { temperature }_{i j}+u_{j}
\end{aligned}
$$

Model 2 Household- and locality-level effects and locality-level random effects:

$$
\begin{aligned}
\operatorname{logit}\left[\operatorname{Pr}\left(y_{i j}=1\right)\right]= & \beta_{0}+\beta_{1} \text { density }_{i j}+\beta_{2} \text { elevation }_{i j} \\
& +\beta_{3} \text { temperature }_{i j} \\
& +\beta_{4} \text { localitytype }_{j}+u_{j}
\end{aligned}
$$

Logit is the link function; $\operatorname{Pr}\left(y_{i j}=1\right)$ is the probability of household infestation; $i$ and $j$ indicate the $i$ th household and the $j$ th locality, $\beta_{1}$ is the vector of regression coefficients for density, where density is kernelsmoothed housing density (households/hectare) categorized by quintiles; $\beta_{2}$ is the vector of regression coefficients for elevation, where elevation (meters above sea level) is categorized by quintiles; $\beta_{3}$ is the regression coefficient for temperature, where temperature is estimated annual median land surface temperature $\left({ }^{\circ} \mathrm{C}\right) ; \beta_{4}$ is the regression coefficient for locality type, where locality type is a dichotomous categorization of localities into

\begin{tabular}{|c|c|c|c|c|c|}
\hline \multirow[t]{2}{*}{ Category } & \multirow[t]{2}{*}{ Locality type } & \multicolumn{2}{|c|}{ Households } & \multicolumn{2}{|r|}{ Localities } \\
\hline & & Number & Percent & Number & Percent \\
\hline Shantytown & Shantytown & 16,595 & 44.58 & 87 & 40.28 \\
\hline \multirow[t]{8}{*}{ Other } & Housing development & 13,293 & 35.71 & 51 & 23.61 \\
\hline & City & 2,308 & 6.20 & 2 & 0.93 \\
\hline & Town & 1,009 & 2.71 & 5 & 2.31 \\
\hline & Hamlet & 567 & 1.52 & 5 & 2.31 \\
\hline & Housing cooperative & 354 & 0.95 & 5 & 2.31 \\
\hline & Annex & 82 & 0.22 & 3 & 1.39 \\
\hline & Rural community & 52 & 0.14 & 1 & 0.46 \\
\hline & Housing association & 15 & 0.04 & 1 & 0.46 \\
\hline \multirow[t]{2}{*}{ No data } & No data & 2,954 & 7.93 & 56 & 25.93 \\
\hline & & 37,229 & 100.00 & 216 & 100.00 \\
\hline
\end{tabular}
shantytown and other; $\beta_{O}$ is the household-level intercept; and $u_{j}$ is the locality-level random effect.

Regression model goodness of fit was assessed using the likelihood ratio test and the Akaike information criteria

Table 3 Categorization scheme for locality type 
(AIC). Spatial autocorrelation in deviance residuals of the least- and best-fit models was evaluated utilizing the mark correlation function $\left(\mathrm{K}_{\mathrm{m}}\right)$ at 25 -meter increments from 0 to 500 meters. A 999-iteration random labeling simulation was executed to identify distances at which regression residual spatial autocorrelation was statistically significant [50].

Stata/IC 12.1 was utilized for statistical analyses [51], and $\mathrm{R}$ version 2.15 .2 was used for spatial analysis of regression residuals.

\section{Competing interests}

The authors declare that they have no competing interests.

\section{Authors' contributions}

SD had primary responsibility for data collection and data analysis, and he wrote the manuscript. KCE guided statistical analysis and manuscript revisions. MLHP provided invaluable assistance with data collection and database management. SRY gave expert guidance on remote sensing analyses. ACC provided counsel on data analysis and manuscript preparation. CRS offered authoritative advice on vector biology and behavior and interpretation of results. As principal investigators for the $\mathrm{NIH}$-funded project in which this study is nested, RHG and CN were responsible for overall study design. As project leader, MZL was integrally involved in data collection, data analysis, interpretation of results, and manuscript preparation. All authors have read and approved this manuscript.

\section{Acknowledgements}

We gratefully acknowledge the invaluable contributions of the following institutions and individuals. The Gerencia Regional de Salud de Arequipa (GRSA) conducted vector surveillance and control and shared these data with us, and we are especially grateful to Juan G. Cornejo del Carpio and Fernando S. Málaga Chavez. The Chagas Disease Working Group in Arequipa, Peru conducted household georeferencing and assisted with database management. Dr. Denise Roe, Professor of Biostatistics at The University of Arizona, provided expert statistical consultation. The Ministerio de Salud del Perú (MINSA), Dirección General de Salud de las Personas (DGSP), Estrategia Sanitaria Nacional de Prevención y Control de Enfermedades Metaxénicas y Otras Transmitidas por Vectores (ESNPCEMOTVS), Dirección General de Salud Ambiental (DIGESA); Gobierno Regional de Arequipa; Pan American Health Organization (PAHO); and Canadian International Development Agency (CIDA) provided financial, logistical, and technical support. We wish to thank the anonymous reviewers for their insightful and invaluable comments, questions, and suggestions. ASTER GDEM V2 is a product of METI and NASA. This work was supported by the National Institutes of Health (http://nih.gov/; 5 P50 Al074285-03 and 04, 3K01Al079162-02S1 to MZL, 5 T37 MD001427 to SD) and the National Institute of Allergy and Infectious Diseases (http://www. niaid.nih.gov/; 1K01Al079162-03 and R01Al101229-01A1 to MZL).

\section{Author details}

${ }^{1}$ School of Geography and Development, The University of Arizona, 409 Harvill Building, 1103 East Second Street, Tucson, Arizona 85721, USA. ${ }^{2}$ Division of Epidemiology and Biostatistics, The University of Arizona, Roy P Drachman Hall, 1295 North Martin Avenue, PO Box 245211, Tucson, Arizona 85724, USA. ${ }^{3}$ Facultad de Ciencias y Filosofia, Universidad Peruana Cayetano Heredia, Avenida Honorio Delgado 430, Urbanización Ingeniería, Lima, Peru. ${ }^{4}$ School of Animal and Comparative Biomedical Sciences, The University of Arizona, 1117 East Lowell Street, Tucson, Arizona 85721, USA. ${ }^{5}$ Bloomberg School of Public Health, Johns Hopkins University, 615 North Wolfe Street, Baltimore, Maryland 21205, USA. ${ }^{6}$ Department of Biostatistics and Epidemiology, University of Pennsylvania, 714 Blockley Hall, 423 Guardian Drive, Philadelphia, Pennsylvania 19104, USA.

Received: 6 August 2013 Accepted: 18 October 2013

Published: 30 October 2013

\section{References}

1. Heymann DL (Ed): Control of communicable diseases manual. 19th edition. Washington, DC: American Public Health Association; 2008.

2. World Health Organization: Control of Chagas disease: Second report of the WHO expert committee. Geneva: World Health Organization; 2002.

3. World Health Organization: The global burden of disease: 2004 update Geneva: World Health Organization; 2008.

4. World Health Organization: Chagas disease: control and elimination (Report by the Secretariat). Geneva: World Health Organization; 2010.

5. World Health Organization: Accelerating work to overcome the global impact of neglected tropical diseases - a roadmap for implementation. Geneva: World Health Organization; 2012.

6. Pinto Dias JC: Southern Cone Initiative for the elimination of domestic populations of Triatoma infestans and the interruption of transfusional Chagas disease. Historical aspects, present situation, and perspectives. Mem Inst Oswaldo Cruz 2007, 102:11-18.

7. World Health Organization: Reporte del grupo de trabajo científico sobre la enfermedad de Chagas. Geneva: World Health Organization; 2007.

8. Moncayo A, Silveira AC: Current epidemiologic trends for Chagas disease in Latin America and future challenges in epidemiology, surveillance and health policy. Mem Inst Oswaldo Cruz 2009, 104:17-30.

9. Tarleton RL, Reithinger R, Urbina JA, Kitron U, Gürtler RE: The challenges of Chagas disease - grim outlook of glimmer of hope? PLoS Med 2007, 4:e332.

10. Mott KE, Desjeux P, Moncayo A, Ranque P, de Raadt P: Parasitic diseases and urban development. Bull World Health Organ 1990, 68:691-696.

11. Levy MZ, Bowman NM, Kawai V, Waller LA, del Carpio JG C, Cordova Benzaquen E, Gilman RH, Bern C: Periurban Trypanosoma cruziinfected Triatoma infestans, Arequipa, Peru. Emerg Infect Dis 2006, 12:1345-1352.

12. Levy MZ, Small DS, Vilhena DA, Bowman NM, Kawai V, Cornejo Del Carpio JG, Cordova-Benzaquen E, Gilman RH, Caryn Bern C, Plotkin JB: Retracing micro-epidemics of Chagas disease using epicenter regression. PLoS Comput Biol 2011, 7:e1002146.

13. Schenone $\mathrm{H}$ : Enfermedad de Chagas en Chile: sectores rurales y periurbanos del area de endemo-enzootia relaciones entre condiciones de la vivienda, infestación triatomidea domiciliaria e infección por Trypanosoma cruzi del vector, del humano y de mamíferos domésticos, 1982-1985. Bol Chil Parasitol 1985, 40:58-67.

14. Tibayrenc M: La maladie de Chagas en Bolivie: données préliminaires sur les cycles domestiques: méthodes simplifiées de captures des triatomes. Cah Orstom (Série Entomologie Médicale et Parasitologie) 1984, 22:51-53.

15. Bowman NM, Kawai V, Levy MZ, Cornejo Del Carpio JG, Cabrera L, Delgado F, Malaga F, Cordova Benzaquen E, Pinedo W, Steurer F, Seitz AE, Gilman $\mathrm{RH}$, Bern C: Chagas disease transmission in periurban communities of Arequipa, Peru. Clin Infect Dis 2008, 46:1822-1828.

16. Vazquez-Prokopec GM, Ceballos LA, Kitron U, Gürtler RE: Active dispersal of natural populations of Triatoma infestans (Hemiptera: Reduviidae) in rural northwestern Argentina. J Med Entomol 2004, 41:614-621.

17. Schofield CJ, Lehane MJ, McEwen PK, Catalá S, Gorla DE: Dispersive flight by Triatoma infestans under natural climatic conditions in Argentina. Med Vet Entomol 1992, 6:51-56

18. Barbu CM, Hong A, Manne JM, Small DS, Quintanilla Calderón JE, Sethuraman K, Quispe-Machaca V, Ancca-Juárez J, del Carpio JG C, Málaga FS, Náquira C, Levy MZ: The effects of city streets on an urban disease vector. PLOS Computational Biology 2013, 9:e1002801.

19. Vallvé SL, Rojo H, Wisnivesky-Colli C: Urban ecology of Triatoma infestans in San Juan, Argentina. Mem Inst Oswaldo Cruz 1996, 91:405-408.

20. Porcasi X, Catalá SS, Hrellac H, Scavuzzo MC, Gorla DE: Infestation of rural houses by Triatoma infestans (Hemiptera: Reduviidae) in southern area of Gran Chaco in Argentina. J Med Entomol 2006, 43:1060-1067.

21. Mott KE, Nuttall I, Desjeux P, Cattland P: New geographical approaches to control of some parasitic zoonoses. Bull World Health Organ 1995, 73:247-257.

22. Stansfield SK, Walsh J, Prata N, Evans T: Information to improve decision making for health. In Disease Control Priorities in Developing Countries. Edited by Jamison DT, Breman JG, Measham AR, Alleyne G, Claeson M, Evans DB, Jha P, Mills A, Musgrove P. Washington, DC: Oxford University Press and The World Bank; 2006:1017-1013.

23. Zeledón R, Rabinovich JE: Chagas disease: an ecological appraisal with special emphasis on its insect vectors. Ann Rev Entomol 1981, 26:101-133. 
24. Lehane MJ, McEwen PK, Whitaker CJ, Schofield CJ: The role of temperature and nutritional status in flight initiation by Triatoma infestans. Acta Trop 1992, 52:27-38.

25. Catalá S: The biting rate of Triatoma infestans in Argentina. Med Vet Entomol 1991, 5:325-333.

26. Gorla DE, Schofield CJ: Population dynamics of Triatoma infestans under natural climatic conditions in the Argentine Chaco. Med Vet Entomol 1989, 3:179-194.

27. Bayer AM, Hunter GC, Gilman RH, Cornejo del Carpio JG, Naquira C, Bern C, Levy MZ: Chagas disease, migration and community settlement patterns in Arequipa, Peru. PLoS Negl Trop Dis 2009, 3:e567.

28. Instituto Nacional de Estadística e Informática del Perú: XI Censo de Población y VI de Vivienda; 2007. http://www.inei.gob.pe.

29. National Aeronautics and Space Administration Earth Observing System Data and Information System. http://reverb.echo.nasa.gov.

30. United States Geological Survey EarthExplorer. http://earthexplorer.usgs.gov.

31. Global Orthorectifed Landsat Data Set. http://www.landsat.org/ortho/.

32. Tucker CJ, Grant DM, Dykstra JD: NASA's global orthorectified Landsat data set. Photogramm Eng Remote Sensing 2004, 70:313-322.

33. Instituto Nacional de Estadística e Informática del Perú: Estadística de Centros Poblados; 1993. http://www.inei.gob.pe.

34. Kelsall JE, Diggle PJ: Non-parametric estimation of spatial variation in relative risk. Stat Med 1995, 14:2335-2342.

35. Diggle PJ: Statistical analysis of spatial point patterns (Second edition). London: Arnold; 2003.

36. Diggle PJ: A kernel method for smoothing point process data. App/ Stat 1985, 34:138-147.

37. Diggle PJ, Chetwynd AG: Second-order analysis of spatial clustering for inhomogeneous populations. Biometrics 1991, 47:1155-1163.

38. The R Project for Statistical Computing. http://www.r-project.org.

39. ESRI. http://www.esri.com.

40. Goslee SC: Analyzing remote sensing data in $\mathrm{R}$ : the landsat package. J Stat Softw 2011, 43:1-25.

41. Song C, Woodcock CE, Seto KC, Lenney MP, Macomber SA: Classification and change detection using Landsat TM data: when and how to correct atmospheric effects? Remote Sens Environ 2000, 75:230-244.

42. Riaño D, Chuvieco E, Salas J, Aguado I: Assessment of different topographic corrections in Landsat-TM data for mapping vegetation types. IEEE Trans Geosci Remote Sens 2003, 41:1056-1061.

43. Jensen JR: Introductory digital image processing: a remote sensing perspective (Third edition) Upper Saddle River. NJ: Pearson Education, Inc; 2005.

44. Jiménez-Muñoz JC, Cristóbal J, Sobrino JA, Sòria G, Ninyerola M, Pons X: Revision of the single-channel algorithm for land surface temperature retrieval from Landsat thermal-infrared data. IEEE Trans Geosci Remote Sens 2009, 47:339-349

45. Barsi JA, Schott JR, Palluconi FD, Hood SJ: Validation of a Web-based atmospheric correction tool for single thermal band images. Proc SPIE 2005, 5882:136-142

46. Chander G, Markham BL, Helder DL: Summary of current radiometric calibration coefficients for Landsat MSS, TM, ETM+, and EO-1 ALI sensors. Remote Sens Environ 2009, 113:893-903.

47. Atmospheric correction parameter calculator. http://atmcorr.gsfc.nasa.gov.

48. Larsen $\mathrm{K}$, Merlo J: Appropriate assessment of neighborhood effects on individual health: integrating random and fixed effects in multilevel logistic regression. Am J Epidemiol 2005, 161:81-88.
49. Merlo J, Chaix B, Ohlsson H, Beckham A, Johnell K, Hjerpe P, Råstam L, Larsen K: A brief conceptual tutorial of multilevel analysis in social epidemiology: using measures of clustering in multilevel logistic regression to investigate contextual phenomena. J Epidemiol Community Health 2006, 60:290-297.

50. Goreaud F: Apports de l'analyse de la structure spatiale en foret tempérée à l'étude et la modélisation des peuplements complexes. In PhD thesis. Paris: Ecole Nationale du Genie Rural, des Eaux et des Forêts; 2000.

51. Stata. http://www.stata.com/

\section{doi:10.1186/1476-072X-12-48}

Cite this article as: Delgado et al:: A country bug in the city: urban infestation by the Chagas disease vector Triatoma infestans in Arequipa, Peru. International Journal of Health Geographics 2013 12:48.

\section{Submit your next manuscript to BioMed Central and take full advantage of:}

- Convenient online submission

- Thorough peer review

- No space constraints or color figure charges

- Immediate publication on acceptance

- Inclusion in PubMed, CAS, Scopus and Google Scholar

- Research which is freely available for redistribution
C Biomed Central 